Requests for reprints should be sent to Dr O M Gibby, Department of Medicine, University of Birmingham, Queen Elizabeth Hospital, Edgbaston, Birmingham B15 2TU.

\section{References}

${ }^{1}$ McIntyre N, Holdsworth CD, Turner OS. New interpretation of oral glucose tolerance. Lancet 1964 ;ii:20-1.

${ }^{2}$ Brown JC, Otte SC. Gastrointestinal hormones and the control of insulin secretion. Diabetes 1978;27:782-9.

${ }^{3}$ Buchanan KD. The gastrointestinal tract and diabetes mellitus. In: Vallance-Owen J, ed. Diabetes, its physiological and biochemical basis. Baltimore: University Park Press, 1975:63-91.

4 Unger RH, Esentrant AM. Enteroinsular axis. Arch Intern Med 1969; $123: 261-6$.

5 Gibby OM, Loke M, Sarson DL, Bloom SR, McMaster P, Calne RY. Distruption of the entero-insular axis in pancreatic transplantation. Regul Pept 1980;suppl 1:542.

${ }^{6}$ Faber OK, Madsbad S, Kehlet H, Binder C. Pancreatic beta cell secretion during oral and intravenous glucose administration. Acta Med Scand 1979 ;suppl 624:61-4.
7 Horwitz DL, Starr JI, Mabo ME, Blackard WG, Rubenstein AM Proinsulin, insulin and C-peptide concentrations in human portal and peripheral blood. F Clin Invest 1975;55:1278-83.

${ }^{8}$ Hales CN, Randle PJ. Immunoassay of insulin with insulin antibodies precipitate. Biochem $\mathcal{F}$ 1963;88:137-46.

- Heding LG. Radioimmunological determination of human C-peptide in serum. Diabetologia 1975;11:541-8.

${ }^{10}$ Katz AI, Rubenstein AH. Metabolism of proinsulin, insulin and Cpeptide in the rat. $f$ Clin Invest 1973;52:1113-21.

11 Stoll RW, Touber JL, Menahan LA, Williams RH. Clearance of porcine insulin, proinsulin and connecting peptide by the isolated rat liver. Proc Soc Exp Biol Med 1970;133:894-6.

12 Caniret B, Krebs BP. C-peptide uptake and excretion by the liver in man. Horm Metab Res 1980;12:229-30.

13 Striffler JS, Curry DL. Effect of fasting on insulin removal by liver of perfused liver-pancreas. Am F Physiol 1979;237:E349-55.

14 Sarson DL, Wood SM, Holder D, Bloom SR. The effect of glucosedependent insulinotropic polypeptide infused at physiological concentrations on the release of insulin in man. Diabetologia 1982;22:33-6.

(Accepted 4 Fanuary 1983)

\title{
Rifampicin reduces effectiveness and bioavailability of prednisolone
}

\author{
W A C MCALLISTER, P J THOMPSON, S M AL-HABET, H J ROGERS
}

\begin{abstract}
Rifampicin is an inducer of hepatic drug metabolising enzymes. This results in interactions with several drugs including oral anticoagulants, hypoglycaemics, and contraceptives. Concurrent treatment with prednisolone and rifampicin is given when tuberculosis coexists with a disease that is sensitive to steroids, when the diagnosis is uncertain, or occasionally in the treatment of severe tuberculosis. Two patients with respiratory disease were treated with both drugs: their condition improved considerably after rifampicin was withdrawn. Seven patients were then studied to assess the effect of rifampicin on the pharmacokinetics of prednisolone. Overall, rifampicin increased the plasma clearance of prednisolone by $45 \%$ and reduced the amount of drug available to the tissues (area under the plasma concentration time curve) by $66 \%$.

The effectiveness of prednisolone may be considerably reduced when rifampicin and prednisolone are used in combination.
\end{abstract}

\section{Introduction}

Rifampicin is an inducer of the hepatic mixed function oxygenase enzymes involved in drug metabolism. ${ }^{2}$ Needle biopsy specimens of the liver from patients receiving rifampicin show an increase in cytochrome $\mathrm{P}_{\mathbf{4 5 0}}{ }^{3}$ and proliferation of smooth endoplasmic reticulum in the hepatocytes. ${ }^{4}$ Rifampicin induces its own metabolism ${ }^{5}$ during continuous treatment as demonstrated by a shortened half life. In addition, rifampicin can accelerate the elimination of the contraceptive pill, ${ }^{6}$ leading to menstrual disturbance and unwanted pregnancy. Tolbutamide, hexobarbitone, ${ }^{7}$ and oral anticoagulants ${ }^{8}$ are other drugs whose metabolism is similarly affected. Deterioration in renal $^{9}$ and allograft function ${ }^{10}$ associated with concomitant rifampicin treatment may be cited as indirect evidence of the effect of this drug on steroid metabolism.

We report on two patients with respiratory disease in whom rifampicin affected metabolism of steroids; and we describe a study of the effects of rifampicin on the pharmacokinetics of prednisolone in seven patients.

\section{Case reports}

CASE 1

A 16 year old boy presented with a year's history of symmetrical polyarthropathy, early morning stiffness, and lassitude. Finger clubbing and a rheumatoid nodule at the elbow were noted, and investigation showed a high erythrocyte sedimentation rate and the presence of rheumatoid factor. Rheumatoid arthritis was diagnosed.

A chest $x$-ray film showed bilateral hilar lymphadenopathy and midzone reticular shadowing. As the most likely diagnosis was thought to be tuberculosis treatment with rifampicin and isoniazid was started. He developed pyrexia, which was ascribed to a possible hypersensitivity reaction to one of these drugs. In an attempt to limit the suspected reaction and because of uncertainty about the diagnosis he was treated additionally with prednisolone $30 \mathrm{mg}$ daily for six weeks. The chest radiographic appearance and symptoms had not improved at the end of this time. Steroid dose was reduced gradually to $10 \mathrm{mg}$ a day but continued at between 7.5 and $15 \mathrm{mg}$ daily concomitantly with
Brompton Hospital, London SW3 6HP

P J THOMPSON, MB, FRACP, research fellow

Department of Clinical Pharmacology, Guy's Hospital Medical School, London SE1 9RT

$S$ M AL-HABET, BPHARM, research fellow

H J ROGERS, PHD, MRCP, reader in clinical pharmacology

Correspondence to: Dr W A C McAllister, Chest Clinic, Westminster Hospital, London SW 1 . 
Pharmacokinetic variables of prednisolone obtained in seven patients during treatment with and without rifampicin

\begin{tabular}{|c|c|c|c|c|c|c|c|c|}
\hline \multirow[b]{2}{*}{ Case No } & \multicolumn{4}{|c|}{ Prednisolone alone } & \multicolumn{4}{|c|}{ With rifampicin } \\
\hline & $\begin{array}{c}\text { Maximum } \\
\text { plasma } \\
\text { concentration } \\
(\mathrm{ng} / \mathrm{ml})\end{array}$ & $\begin{array}{c}\text { Area } \\
\text { under curve } \\
(\mathrm{ng} / \mathrm{ml} / \mathrm{h})\end{array}$ & $\begin{array}{c}\text { Plasma } \\
\text { half life } \\
\text { (h) }\end{array}$ & $\begin{array}{c}\text { Systemic } \\
\text { clearance } \\
(\mathrm{l} / \mathrm{h})\end{array}$ & $\begin{array}{c}\text { Maximum } \\
\text { plasma } \\
\text { concentration } \\
(\mathrm{ng} / \mathrm{ml})\end{array}$ & $\begin{array}{c}\text { Area } \\
\text { under curve } \\
(\mathrm{ng} / \mathrm{ml} / \mathrm{h})\end{array}$ & $\begin{array}{c}\text { Plasma } \\
\text { half life } \\
\text { (h) }\end{array}$ & $\begin{array}{c}\text { Systemic } \\
\text { clearance } \\
(\mathrm{l} / \mathrm{h})\end{array}$ \\
\hline $\begin{array}{l}1 \\
2 \\
3 \\
4 \\
5 \\
6 \\
7\end{array}$ & $\begin{array}{l}478 \\
375 \\
490 \\
434 \\
905\end{array}$ & $\begin{array}{l}4560 \\
1892 \\
2951 \\
1792 \\
2302\end{array}$ & $\begin{array}{l}5 \cdot 74 \\
3 \cdot 22 \\
4 \cdot 17 \\
2 \cdot 35 \\
2 \cdot 43\end{array}$ & $\begin{array}{r}4 \cdot 4 \\
10 \cdot 6 \\
6 \cdot 8 \\
11 \cdot 2 \\
8 \cdot 7\end{array}$ & $\begin{array}{l}180 \\
424 \\
434 \\
463 \\
493 \\
556 \\
386\end{array}$ & $\begin{array}{l}1028 \\
1535 \\
1385 \\
1410 \\
1094 \\
1380 \\
1499\end{array}$ & $\begin{array}{l}4.55 \\
2.52 \\
3.53 \\
4.02 \\
1.96 \\
1.81 \\
2.84\end{array}$ & $\begin{array}{l}19.5 \\
13.0 \\
14.4 \\
14 \cdot 2 \\
18.3 \\
14.5 \\
13.3\end{array}$ \\
\hline Mean \pm SD & $536 \cdot 4 \pm 188$ & $2699 \pm 1015$ & $3 \cdot 58 \pm 1 \cdot 26$ & $8 \cdot 3 \pm 2.5$ & $419 \cdot 4 \pm 110$ & $1333 \pm 169$ & $3.03 \pm 0.89$ & $15 \cdot 3 \pm 2 \cdot 19$ \\
\hline
\end{tabular}

the antituberculous treatment for a year, with no further change in his condition. An open lung biopsy was performed, disclosing a mixed mural and desquamative interstitial pneumonia consistent with fibrosing alveolitis associated with rheumatoid arthritis.

He was transferred to the Brompton Hospital, where the prednisolone dose was increased to $30 \mathrm{mg}$ daily (same as the original dose) and the antituberculous treatment was stopped. Within six weeks his symptoms and the chest $x$-ray shadowing had improved considerably; this improvement was maintained when the steroid dosage was reduced. It was assumed that rifampicin had altered the metabolism of prednisolone, and this was confirmed by a pharmacokinetic study (see below and case 1, table), which showed a fourfold increase in the area under the prednisolone concentration time curve once rifampicin was stopped.

\section{CASE 8}

A 45 year old West Indian man presented with a dry cough and shortness of breath on exercise. Clinical examination was normal but bilateral nodular shadowing of the mid and lower zones was present. No abnormality was found on clinical examination. Serum angiotensin converting enzyme activity was raised $(70 \mathrm{nmol} / \mathrm{ml} / \mathrm{min})$, and sputum was negative for acid-fast bacilli. A scalene node biopsy showed multiple granulomas with slight caseation.

As it was difficult to determine whether the diagnosis was sarcoidosis or tuberculosis treatment with rifampicin, isoniazid, ethambutol, and prednisolone ( $40 \mathrm{mg}$ daily) was started and continued for three months without improvement in either the symptoms or the chest $x$-ray film. At this time he developed a rash; rifampicin was stopped as hypersensitivity was suspected, and treatment was continued otherwise unchanged. Within a month the symptoms and radiographic appearance had resolved considerably, the radiograph being entirely normal within two months. Ethambutol and isoniazid were stopped and the steroid dose gradually reduced to $10 \mathrm{mg}$ daily with no recrudescence of the disease during a two year follow up period. A diagnosis of sarcoidosis was substantiated by the response to steroids after withdrawal of rifampicin. The abrupt resolution of the radiographic shadowing in the month after rifampicin was stopped together with the lack of improvement during three preceding months of treatment with high dose steroids is strong evidence that rifampicin interferes with the effectiveness of prednisolone.

\section{Subsequent study}

\section{SUBJECTS AND METHODS}

All patients studied were receiving treatment for pulmonary tuberculosis consisting of rifampicin $(8 \mathrm{mg} / \mathrm{kg})$, isoniazid $(4 \mathrm{mg} / \mathrm{kg})$, and ethambutol $(15 \mathrm{mg} / \mathrm{kg}$ ) or rifampicin and isoniazid alone. Prednisolone was administered as an adjunct to this treatment either because of some particular reason associated with the nature of the tuberculosis or because the diagnosis was unclear. Patients were therefore all receiving prednisolone and antituberculous treatment at the behest of their physicians.

The pharmacokinetics of prednisolone were studied twice in five patients, when they were taking prednisolone alone and on a separate occasion when they were also taking rifampicin. Two further patients were studied only while taking rifampicin and prednisolone as it proved impossible to perform the second study. The age range was 16-65 years and weight range $45-75 \mathrm{~kg}$. All subjects had normal renal and hepatic function before the study, but transient slight rises in hepatic enzyme activities were seen at the onset of antituberculous $\frac{\rho}{\vec{D}}$ treatment. The study of prednisolone alone was performed either $\varnothing$ before antituberculous treatment was started or at least a month after $\stackrel{\varpi}{\omega}$ it was stopped to allow any residual effect of rifampicin to be $\vec{\theta}$ eliminated. Two subjects (cases 2 and 3) were studied before and three (cases 1, 4, and 5) after antituberculous treatment (table). All patients $\overrightarrow{\vec{\omega}}$ had taken prednisolone for at least five days before the day of the study $\sigma^{\circ}$ of prednisolone alone. All patients had taken rifampicin and pred- $\bar{T}$ nisolone for at least a month before the study of the two drugs.

The patients were given $20 \mathrm{mg}$ prednisolone at 0800 after an over- $\stackrel{\infty}{\infty}_{\infty}$ night fast. No food or beverages were taken over the ensuing three hours, and meals thereafter were identical on both study days. Blood $\mathrm{E}^{\circ}$ samples were taken via an indwelling cannula at 0,15 , and 40 minutes o and at one, two, three, four, six, and eight hours; plasma was stored at $i$ $-20^{\circ} \mathrm{C}$.

Plasma prednisolone concentration was measured by quantitative $\omega$ thin layer chromatography with fluorescence detection using a method described previously ${ }^{11}$ and later further modified.12 The within assay $\vec{\theta}$ coefficient of variation and bias have been described.12

\section{PHARMACOKINETICS}

Pharmacokinetic variables were calculated from the measured prednisolone concentrations using conventional methods. ${ }^{13}$ The total absorption of a drug is proportional to the plasma concentrations achieved and the length of time these concentrations persist in the plasma. One variable that characterises this phenomenon is the area under the plasma concentration time curve; this is a model-independent variable that is based solely on observations without any interpretation regarding mechanism. Systemic clearance is a measure of $\overrightarrow{\overrightarrow{0}}$ elimination of the drug by whatever means from the body. The area 3 under the curve was estimated using the linear trapezoidal rule with $\supset$ addition of an appropriate correction for the infinite portion of the curve. The apparent first order elimination rate constant (k) was determined by linear regression of 1 (n (plasma concentration) on time. The plasma half life was estimated as equal to $0.693 \mathrm{k}$.

Studies ${ }^{14}{ }^{15}$ have shown that intravenous and oral prednisolone have $\dot{\sigma}$ roughly equivalent bioavailability, therefore permitting calculation of systemic clearance from oral administration with the assumption that $\delta$ $\mathbf{F}=1$. In an oral study the estimate of bioavailability is relative and a 3 reference oral dose (in this case without rifampicin) is taken as the 0 standard for comparison. The apparent estimates of systemic clearance were calculated from $\mathrm{F}$ (dose)/area under curve, where $\mathrm{F}$ is the $\mathcal{N}$ bioavailability fraction. The maximum plasma concentration was taken $D$ direct from the measurements in each patient.

These pharmacokinetic variables were compared for prednisolone with and without concurrent rifampicin treatment. Statistical signi- 0 ficance for all the patients was determined using the Mann-Whitney $N^{\omega}$ $\mathrm{U}$ test, which particularly allows for unpaired samples. Additionally the paired results were assessed by two way analysis of variance. 0 Unpaired significance tests are more stringent than simple paired significance tests.

RESULTS

The table shows the values of the pharmacokinetic variables of prednisolone in all the patients studied during concurrent treatment 8 with rifampicin and when no rifampicin was given. There was a significant increase in the systemic clearance and reduction in the area under the curve for prednisolone when rifampicin was given: the 
mean area under the curve was reduced to less than half $(66 \%$ reduction) $(p=0.001)$ and the mean clearance increased by $45 \%$ $(p=0.001)$. This effect was seen irrespective of whether the study of prednisolone alone was before or after the course of antituberculous treatment and was a consistent finding in all subjects in whom both treatments were given. The plasma half life and maximum plasma concentration were unaltered. There was a wide interindividual variation in the plasma half life of prednisolone, which agrees with the findings of others. ${ }^{16}$

\section{Discussion}

There is a wide range of conditions that is responsive to steroids and during the course of which tuberculosis may develop and treatment with rifampicin be added. Such conditions, for which steroids are often essential, are as varied as asthma, systemic lupus and other connective tissue disorders, fibrosing alveolitis, and glomerulonephritis; the problem also arises in patients receiving post-transplantation regimens and cancer chemotherapy. Corticosteroids are occasionally used temporarily as part of the treatment of tuberculosis or in reducing oedema in those with a cerebral or spinal tuberculous abscess impinging dangerously on neurological structures. Alternatively the combination of rifampicin and prednisolone may be used when the diagnosis is not clear and tuberculosis cannot be excluded. In particular, it can be difficult to distinguish histologically and clinically between tuberculosis and sarcoidosis. If rifampicin and prednisolone are used in combination in any of these circumstances the steroid is exerting considerably less effect than might be expected. The case histories above illustrate this point and underline how easily failure to respond to treatment may be ascribed to the severity of the illness rather than to drug interaction. It is important to note that once rifampicin was stopped in case 8 the patient's condition improved despite continued treatment with ethambutol and isoniazid, implying that rifampicin alone was exerting the deleterious effect.

Possible clinical effects of rifampicin in patients dependent on prednisolone have been reported. ${ }^{910}$ Edwards et al ${ }^{17}$ described a patient with Addison's disease who required an increased corticosteroid dose while receiving rifampicin. However, apart from one case report ${ }^{9}$ of reduced half life of prednisolone in a young boy determined by using a radiolabelled tracer no quantitative studies of the effect of rifampicin on the metabolism of prednisolone have been carried out.

Our pharmacokinetic study shows a pronounced effect of rifampicin on the metabolism of prednisolone. Although rifampicin is a hepatic enzyme inducer, the precise mechanism of the interaction cannot be distinguished. The core observation is that the area under the prednisolone curve, which is a model independent variable based solely on observations without any interpretation as to mechanism, is reduced with rifampicin. The area under the curve roughly represents the amount of drug available to the tissues, and a $66 \%$ reduction in this might have serious consequences if not compensated for by adjustment of the dosage. Not only may patients in whom disease control depends on prednisolone suffer exacerbation of disease, but a condition that responds to steroids may be overlooked if rifampicin is administered concurrently. The consequences are particularly important as in many cases there are no viable alternatives to corticosteroid treatment and the findings above are probably qualitatively true for all steroids. Rifampicin remains an extremely useful antituberculous agent, and an alternative to changing to other chemotherapy would be to at least double the dose of prednisolone if rifampicin is to be administered simultaneously.

We thank Professor Turner Warwick and Dr J O Warner and physicians at the Brompton Hospital for allowing us to study and report on their patients.

Requests for reprints should be sent to Dr W A C McAllister, Chest Clinic, Westminster Hospital, London SW1.

\section{References}

1 Ohnhaus EE, Park BK. Measurement of urinary 6- $\beta$ hydroxycortisol excretion as an in vivo parameter in the clinical assessment of the microsomal enzyme inducing capacity of antipyrine, phenobarbitone and rifampicin. Eur f Clin Pharmacol 1979;15:139-45.

2 Toverud EL, Boobis AR, Brodie MS, et al. Differential induction of antipyrine metabolism by rifampicin. Eur $\mathcal{F}$ Clin Pharmacol 1981 ;21 :155-60.

${ }^{3}$ Schoene B, Fleischman RA, Remmer H, Von Oldershausen HF. Determination of drug metabolising enzymes in needle biopsies of human liver. Eur f Clin Pharmacol 1973;4:65-73.

4 Jezequel AM, Orlandi F, Tenconi LT. Changes of the smooth endoplasmic reticulum induced by rifampicin in human and guinea pig hepatocytes. Gut 1971 ;12:984-7.

5 Acocella G, Bonollo L, Garimoldi M, Mainardi M, Tenconi T, Nicolis FG. Kinetics of rifampicin and isoniazid administered alone and in combination to normal subjects and patients with liver disease. Gut $1972 ; 13: 47-53$.

${ }^{6}$ Nocke-Finck L, Breuer H, Reimers D. Effects of antibiotics on oestrogen excretion in women taking oral contraceptives. Acta Endocrinol 1973; suppl 177:136.

7 Zilly W, Breimer DD, Richter E. Induction of drug metabolism in man after rifampicin treatment measured by increased hexobarbitone and tolbutamide clearance. Eur $\mathcal{f}$ Clin Pharmacol 1975;9:219-27.

${ }^{8} \mathrm{O}$ 'Reilly RA. Interaction of sodium, warfarin and rifampicin studies in man. Ann Intern Med 1974;81:337-40.

- Hendrickse W, McKiernan J, Pickup M, Lowe J. Rifampicin-induced non-responsiveness to corticosteroid treatment in nephrotic syndrome. Br Med f 1979;i:306.

${ }^{10}$ Buffington GA, Dominguez JH, Piering WF, Herbert LA, Kaufman HM, Leman J. Interaction of rifampicin and glucocorticoids. $\mathcal{F} A M A 1976 ; 236$ : 1958-60.

${ }^{11}$ Morrison PJ, Bradbrook ID, Rogers HJ. Plasma prednisolone levels from enteric and non-enteric coated tablets estimated by an original technique. Br f Clin Pharmacol 1977;4:597-603.

12 Al-Habet SMH, McAllister WAC, Collins JV, Rogers HJ. Comparison of radioimmunoassay and thin layer chromatography assay methods for estimation of plasma prednisolone concentrations. F Pharmacol Methods $1981 ; 6: 137-42$.

${ }^{13}$ Gibaldi M, Perrier D. Pharmacokinetics. New York: Marcel Dekker, 1975.

14 Tanner A, Bochner F, Caffin J, Halliday J, Powell L. Dose dependent prednisolone kinetics. Clin Pharmacol Ther 1979;25:571-8.

15 Al-Habet S, Rogers HJ. Pharmacokinetics of intravenous and oral prednisolone. Br $\mathcal{F}$ Clin Pharmacol 1980;10:503-8.

${ }^{16}$ Gambertoglio JG, Amend WJC, Benet LZ. Pharmacokinetics and bioavailability of prednisone and prednisolone in healthy volunteers and patients: a review. F Pharmacokinet Biopharm 1980;5:257-70.

17 Edwards OM, Courtenay-Evans RJ, Galley JM, Hunter J, Tait AD. Changes in cortisol metabolism following rifampicin therapy. Lancet 1974 ;ii :549-51.

(Accepted 4 Fanuary 1983)

ONE HUNDRED YEARS AGO Dr. Horace Dobell, in a letter published in the Times of September 18th, draws attention to the bad effects of the "braces system of suspension" for women's dress. He urges that the hips, and not the shoulders, are the best part of the human frame for the support of weight. He adds that "braces restrict the elevation and antero-posterior expansion of the chest; and important as these movements are to men, they are far more so to women." There is doubtless much truth in Dr. Dobell's remarks, but we trust that his assertion that the system of suspension of the clothes from the shoulders is the outcome of the arguments used by "dress reformers" against tight lacing, will not be seized by the ladies as a statement in favour of continuing the use of stays. The evils referred to by Dr. Dobell, doubtless are often produced by the use of braces, and especially when a heavy weight is suspended. This weight is often unnecessarily great in consequence of the looseness of ladies' clothing. If, instead of hanging a quantity of loose clothes round the legs, the garments covering these extremities were chiefly close-fitting, the weight of the clothing might be very much lessened, because when close to the body they preserve the warmth much better than when surrounding the legs loosely. The principle of dual garments might be carried on without altering the external appearance of female dress; for, with the use of warm, close-fitting drawers or trousers, the outer skirts might be made in the usual manner, but of much less thickness and weight. Many ladies now wear neither stays nor suspenders, and yet experience no difficulty in supporting their skirts, chiefly upon the hips. (British Medical fournal, 1883 ;ii:640.) 